\title{
ANALISIS PERENCANAAN SUMBER DAYA MANUSIA (SDM) KESEHATAN PUSKESMAS DENGAN METODE WORKLOAD INDICATORS OF STAFFING NEEDS (WISN) DI KABUPATEN LOMBOK BARAT
}

\author{
Ni Wayan Sri Wangi*, Agusdin ${ }^{* *}$, Siti Nurmayanti*** \\ Fakultas Kedokteran Universitas Islam Al-Azhar \\ Jl. Unizar No. 20 Turida Mataram \\ Email: drniwayansriwangi@gmail.com
}

\begin{abstract}
ABSTRAK
Penelitian ini bertujuan menganalisis perencanaan sumber daya manusia kesehatan (SDMK) Puskesmas dengan menghitung beban kerja, kebutuhan jumlah dan kompetensi setiap unit dan kategori SDMK Puskesmas serta kebutuhan pengembangannya di Kabupaten Lombok Barat. Penelitian ini merupakan penelitian deskriptif dengan pendekatan kuantitatif dan kualitatif. Analisis data kuantitatif menggunakan metode Workload Indicators of Staffing Needs (WISN). Analisis data kualitatif menggunakan metode dari Miles dan Huberman melalui analisis kebutuhan organisasi, pekerjaan dan personal. Sampel Puskesmas dan informan penelitian dipilih dengan metode purposive sampling. Puskesmas Gunung Sari dan Meninting terpilih menjadi sampel penelitian. Seluruh SDMK Puskesmas yang berjumlah 168 orang dijadikan responden dan 10 orang diantaranya dipilih menjadi informan penelitian. Teknik pengumpulan data yang digunakan adalah dokumentasi, angket, wawancara mendalam dan Focus Group Discussion (FGD). Hasil penelitian menunjukkan 8 unit kerja dan 8 kategori tenaga di Puskesmas Gunung Sari serta 7 unit kerja dan 7 kategori tenaga di Puskesmas Meninting memiliki beban kerja tinggi (rasio WISN<1). Beban kerja rendah (rasio WISN>1) didapatkan pada 4 kategori tenaga di Puskesmas Gunung Sari serta 1 unit kerja dan 4 kategori tenaga di Puskesmas Meninting. Kebutuhan seluruh SDMK Puskesmas Gunung Sari sebanyak 114 orang, yang tersedia sebanyak 98 orang sehingga terdapat kekurangan 16 orang. Puskesmas Meninting membutuhkan 87 orang tenaga, yang tersedia 70 orang sehingga masih terdapat kekurangan 17 orang. Hasil analisis kebutuhan pengembangan SDMK menunjukkan kebutuhan peningkatan pendidikan Diploma III bagi perawat, pelatihan kegawatdaruratan dan penunjang diagnostik bagi dokter umum dan perawat. Pelatihan manajemen dibutuhkan oleh bendahara dan tenaga pengadaan barang dan jasa. Pelatihan administrasi pelayanan dibutuhkan oleh seluruh staf Puskesmas. Penelitian ini merekomendasikan Puskesmas untuk membuat perencanaan perekrutan, rotasi antar unit kerja dan pengembangan SDMK sesuai dengan hasil analisis WISN dan kebutuhan pengembangan SDMK Puskesmas di Kabupaten Lombok Barat.
\end{abstract}

Kata Kunci : Beban Kerja, WISN, Kebutuhan Pengembangan SDMK, Puskesmas.

\section{PENDAHULUAN}

Pembangunan

kesehatan

merupakan bagian dari pembangunan

nasional yang bertujuan meningkatkan

derajat kesehatan masyarakat setinggi-

tingginya. Keberhasilan pembangunan

kesehatan sangat ditentukan oleh adanya

sumber daya manusia (SDM) dimana

SDM memberikan kontribusi sebesar

$80 \%$ dari keseluruhan faktor yang terkait

dalam pembangunan kesehatan
(Dharmayuda, 2014). Subsistem SDM kesehatan dalam Sistem Kesehatan

Nasional (SKN) bertujuan agar tersedianya SDM kesehatan yang kompeten sesuai kebutuhan, terdistribusi secara adil dan merata serta didayagunakan secara optimal dalam mendukung penyelenggaraan pembangunan kesehatan dan sebagai unsur utama yang mendukung subsistemsubsistem kesehatan lainnya (Depkes, 
2009). Subsistem sumber daya manusia mengandung berbagai upaya pengembangan dan pemberdayaan sumber daya manusia kesehatan. Upaya tersebut meliputi upaya perencanaan, pengadaan, pendayagunaan, serta pembinaan dan pengawasan mutu sumber daya manusia kesehatan untuk mendukung penyelenggaraan pembangunan kesehatan (Peraturan Pemerintah No. 64, 2012).

Perencanaan sumber daya manusia (human resources planning) adalah kegiatan menghimpun dan menggunakan informasi untuk menunjang keputusan investasi sumber daya dalam berbagai aktivitas sumber daya manusia. Perencanaan SDM Kesehatan (SDMK) dilakukan dengan menyesuaikan kebutuhan pembangunan kesehatan, baik lokal, nasional maupun global. Perhitungan kebutuhan SDMK dapat berpedoman kepada tiga metode yaitu: analisis beban kerja, standar ketenagaan minimal, dan rasio jumlah penduduk (Permenkes No.33, 2015). Rencana kebutuhan tenaga kesehatan dibatasi hanya pada 13 (tiga belas) jenis tenaga kesehatan, yaitu dokter spesialis, dokter umum, dokter gigi, perawat, bidan, perawat gigi, apoteker, asisten apoteker, sanitarian, tenaga gizi, tenaga kesehatan masyarakat, tenaga keterapian fisik, dan tenaga keteknisian medis (Kepmenko Bidang Kesra No.54, 2013). Adapun kebutuhan SDMK non kesehatan disesuaikan kategorinya dengan kebutuhan fasilitas kesehatan yang ada. Menurut data dari Badan Pusat Pengembangan Sumber Daya Manusia (PPSDM) Kementrian Kesehatan (Kemenkes) tahun 2011, di Puskesmas se-Indonesia pada tahun 2010 telah tersedia 14.840 dokter umum, 6.125 dokter gigi, 78.675 perawat, 7.704 perawat gigi, 83.000 bidan, 6.351 orang S-1 Farmasi/Apoteker, 8.601 asisten apoteker, 1.356 tenaga kesehatan masyarakat, 6.031 sanitarian, 7.547 tenaga gizi, dan 2.609 tenaga teknis medis. Dengan melihat standar ketenagaan Puskesmas yang berlaku, angka ini menunjukkan kekurangan tenaga kesehatan sebanyak 149 untuk tenaga dokter umum, 2.093 untuk dokter gigi, 280 orang tenaga perawat gigi, 21.797 tenaga bidan, 5045 untuk asisten apoteker 13.019 tenaga kesehatan masyarakat, 472 tenaga sanitarian, 303 tenaga gizi dan 5.771 tenaga teknis medis (Kepmenko Bidang Kesra No. 54, 2013).

Gambaran kebutuhan tenaga kesehatan secara nasional selama ini dihitung dengan menggunakan metode rasio tenaga kesehatan terhadap nilai tertentu, yaitu sesuai dengan perkembangan jumlah penduduk. Ambang batas rasio untuk tenaga dokter, perawat dan bidan adalah 2,3 per 100.000 penduduk. Jika dilihat dari rasio jumlah 
ketersediaan tenaga kesehatan per 100.000 penduduk di Kabupaten Lombok Barat, semua kategori tenaga kesehatan yang ada belum dapat memenuhi target kebutuhan tenaga kesehatan yang telah ditetapkan secara nasional. Permasalahan dalam hal perencanaan SDM di Puskesmas adalah sulitnya memenuhi indikator jumlah tenaga yang ideal per 100.000 penduduk. Metode rasio belum dapat mencerminkan kebutuhan riil tenaga kesehatan berdasarkan beban kerja. Perencanaan kebutuhan tenaga kesehatan dengan melakukan analisis beban kerja menurut Peraturan Menteri Kesehatan (Permenkes) Nomor 75 Tahun 2014 tentang Pusat Kesehatan Masyarakat (Puskesmas) dirasa lebih tepat. Salah satu metode yang dapat dipakai untuk menghitung beban kerja dan mengestimasi jumlah kebutuhan SDMK adalah dengan metode Workload Indicators of Staffing Need (WISN). Metode ini akurat dipakai untuk menghitung kebutuhan SDMK berdasarkan pada beban pekerjaan nyata yang dilaksanakan oleh setiap kategori SDMK pada tiap unit kerja di fasilitas pelayanan kesehatan.

Hasil WISN menggambarkan permasalahan perencanaan SDM dari segi beban kerja, jumlah kebutuhan tenaga dan distribusinya. Salah satu komponen yang tidak kalah penting adalah kompetensi tenaga. Dalam menganalisis hasil WISN komponen ini erat kaitannya dengan pengembangan SDMK. Untuk membuat perencanaan pengembangan SDM diperlukan data jenis pengembangan yang dibutuhkan. Data ini dapat diperoleh melalui analisis kebutuhan pengembangan (needs analysis). Analisis kebutuhan pengembangan SDM dapat dilakukan melalui pendekatan analisis organisasi (organizational analysis) yang menilai unit atau bagian dari organisasi yang memerlukan pengembangan, analisis tugas (task/job analysis) yang mengidentifikasi pekerjaan atau skill apa yang harus dipelajari, dan analisis orang (person analysis) yang membantu memilih siapa orang yang akan dikembangkan (Simamora, 2006:289292).

Adapun masalah penelitian dirumuskan sebagai berikut :

1. Bagaimanakah beban kerja masingmasing unit kerja dan kategori SDM Kesehatan Puskesmas di Kabupaten Lombok Barat?

2. Berapakah kebutuhan jumlah dan kompetensi SDM masing-masing unit kerja di Puskesmas Kabupaten Lombok Barat?

3. Apakah jenis pengembangan SDM yang dibutuhkan Puskesmas di Kabupaten Lombok Barat? 


\section{LANDASAN TEORI}

Perencanaan Sumber Daya Manusia

\section{Kesehatan}

Pengelolaan Sumber Daya Manusia (SDM) kesehatan khususnya dalam perencanaan kebutuhan SDM kesehatan selama ini masih bersifat administratif kepegawaian dan belum dikelola secara profesional. Perencanaannya masih bersifat top down dari pusat, belum bottom up (dari bawah), belum sesuai dengan kebutuhan organisasi dan kebutuhan nyata di lapangan, serta belum berorientasi jangka panjang. Seperti penelitian yang dilakukan Benhard,dkk ( 2015) yang menemukan belum adanya persamaan persepsi antara Dinas Kesehatan dengan Puskesmas dalam hal alat ukur dan metode perencanaan SDMK. Perencanaan SDM kesehatan diharapkan berorientasi pada Rencana Pembangunan Jangka Panjang yang disusun di Propinsi. Perencanaan SDMK merupakan proses yang secara sistematis mengkaji keadaan, sumber daya manusia untuk memastikan bahwa jenis, jumlah, dan kualitas dengan keterampilan yang tepat akan tersedia pada saat mereka dibutuhkan. Perencanaan kebutuhan SDMK bertujuan untuk menghasilkan rencana kebutuhan SDMK yang tepat meliputi jenis, jumlah, kualifikasi sesuai dengan kebutuhan organisasi berdasarkan metode perencanaan yang sesuai dalam rangka mencapai tujuan pembangunan kesehatan (Permenkes No. 33, 2015).

Metode perencanaan kebutuhan SDMK :

1. Metode berdasarkan institusi, yang digunakan adalah :

a. Analisis Beban Kerja Kesehatan (ABK Kes).

b. Standar ketenagaan Minimal.

2. Metode berdasarkan wilayah

Metode yang digunakan adalah metode 'ratio penduduk' yakni rasio tenaga kesehatan terhadap jumlah penduduk di suatu wilayah.

\section{Analisis Beban Kerja}

Menurut Wideman (2002) dalam Hardjawinata (2006) mendefinisikan beban kerja adalah jumlah unit kerja yang ditugaskan pada satu sumber daya dalam periode waktu tertentu. Kebutuhan ini akan berkembang menyesuaikan dengan tuntutan dan perkembangan organisasi sehingga perlu dilakukan penilaian tiap tahunnya. Berbagai metode yang telah dikembangkan dapat dijadikan patokan dalam melakukan analisis beban kerja. Metode yang paling akurat untuk peramalan jangka pendek saat ini adalah dengan menghitung beban kerja (workload) yang merupakan analisis pekerjaan terhadap beban kerja yang perlu disesuaikan (Simamora, 2006:141). Workload Indicators of Staffing Need (WISN) merupakan sebuah standar pengukuran kebutuhan tenaga kesehatan berdasarkan indikator beban kerja yang 
pertama kali di ujicobakan sekitar tahun 1998. Metode WISN adalah alat manajemen sumber daya yang menghitung kebutuhan staf berdasarkan beban kerja untuk kategori staf tertentu dan jenis fasilitas kesehatan. Metode WISN memiliki kelebihan yaitu mudah digunakan baik secara teknis, komprehensif, realistis serta memberikan kemudahan dalam menentukan variasi kebutuhan SDM dalam berbagai tipe layanan kesehatan seperti puskesmas maupun rumah sakit.

Menurut Shipp (1998), langkah untuk menghitung tenaga berdasarkan WISN ada 5 langkah yaitu:

\section{Menetapkan Waktu Kerja Tersedia} (WKT)

Tujuannya untuk menentukan waktu kerja efektif selama satu tahun, untuk masing-masing kategori SDM yang akan kita hitung.

\section{Rumusnya:}

Waktu kerja tersedia $=\{\mathrm{A}-(\mathrm{B}+\mathrm{C}+\mathrm{D}+\mathrm{E})\} \mathrm{XF}$

Keterangan:

$\mathrm{A}=$ Jumlah hari kerja yang mungkin dalam setahun

$\mathrm{B}=$ Cuti tahunan

$\mathrm{C}=$ Pendidikan dan pelatihan

$\mathrm{D}=$ Hari libur nasional

$\mathrm{E}=$ Ketidakhadiran kerja (rata-rata ketidakhadiran kerja selama satu tahun karena alasan sakit, tidak masuk kerja dengan atau tanpa alasan)
$\mathrm{F}=$ Waktu kerja (waktu kerja dalam satu hari)

\section{Menentukan Unit Kerja dan}

\section{kategori SDM yang dihitung}

Bertujuan menetapkan unit kerja dan kategori SDM yang bertanggung jawab memberikan pelayanan kesehatan.

Informasi ini bisa didapatkan dari:

a. Data pegawai berdasarkan pendidikan yang bekerja pada tiap unit kerja

b. Peraturan perundangan yang berkaitan dengan jabatan fungsional SDM kesehatan

c. Standar profesi, standar pelayanan, dan standar operating prosedur pada tiap unit kerja.

\section{Menyusun Standar Beban Kerja}

Merupakan volume atau kuantitas beban kerja selama 1 tahun per kategori SDM. Standar beban kerja untuk satu kegiatan pokok dihitung berdasarkan waktu rata-rata yang dibutuhkan untuk menyelesaikan kegitan tersebut dan waktu kerja yang tersedia.

Rumusnya:

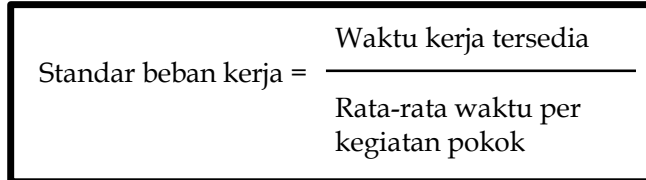

Data yang diperlukan antara lain:

a. Waktu yang tersedia

b. Bagan struktur organisasi

c. Kegiatan pokok (kegiatan pokok dan uraian kegiatan, serta tanggung jawab masing-masing kategori SDM)

d. Rata-rata waktu untuk menyelesaikan 
jenis kegiatan pokok

e. Standar profesi

f. Menetapkan waktu berdasarkan kesepakatan

\section{Menyusun standar kelonggaran} dan faktor kelonggaran.

Bertujuan memperoleh faktorfaktor kelonggaran setiap kategori SDM meliputi jenis kegiatan dan waktu penyelesaian suatu kegiatan yang tidak terkait langsung dengan pelayanan pasien. Pengamatannya meliputi:

a. Kegiatan-kegiatan yang tidak terkait langsung dengan pelayanan pasien

b. Frekuensi tiap kegiatan dalam satuan hari, minggu dan bulan

c. Waktu rata-rata yang dibutuhkan untuk menyelesaikan kegiatan tersebut

Rumusnya:

$$
\text { Standar kelonggaran }=\frac{\begin{array}{l}
\text { Rata-rata waktu } \\
\text { perfaktor kelonggaran }
\end{array}}{\text { Waktu yang tersedia }}
$$

Faktor Kelonggaran Kategori (FKK) digunakan sebagai pengali dalam penentuan jumlah keseluruhan tenaga kesehatan yang dibutuhkan pada langkah WISN berikutnya. FKK dihitung dengan cara sebagai berikut :

a. Mengubah Standar Kelonggaran Kategori dari setiap kegiatan penunjang yang penting menjadi persentase waktu kerja.

b. Menjumlahkan semua Standar Kelonggaran Kategori tersebut c. Menggunakan rumus matematik untuk mendapatkan FKK, sebagai berikut :

FKK $=1$ dibagi dengan $\{1$ dikurangi (Total SKK yang dibagi 100)\}

memperhitungkan waktu kerja yang digunakan beberapa tenaga kesehatan dalam setiap kategori tenaga untuk kegiatan-kegiatan tambahan. FKI menghitung berapa petugas yang dibutuhkan untuk melakukan kegiatankegiatan ini secara "setara purna waktu" (whole time equivalent, WTE). FKI ditambahkan dalam perhitungan akhir dari keseluruhan kebutuhan staf. Perhitungannya sebagi berikut :

a. Mengalikan masing-masing Standar Kelonggaran Individu dengan jumlah orang yang melakukan kegiatan tersebut,

b. Menjumlahkan semua hasil yang diperoleh diatas, kemudian membagi hasil tersebut dengan Waktu Kerja Tersedia (WKT).

c. Apabila jumlah tenaga yang melaksanakan suatu kegiatan bervariasi antar kegiatan, maka perlu dilakukan perhitungan tersendiri atas masing-masing kelompok kegiatan yang dikerjakan oleh jumlah tenaga yang sama, dan kemudian menjumlahkannya.

d. Menghitung kebutuhan tenaga per unit kerja Bertujuan memperoleh jumlah dan kategori SDM yang dibutuhkan untuk menyelenggarakan upaya 
kesehatan wajib dan upaya pengembangan dalam kurun waktu satu tahun (Depkes, 2004).

\section{Rumusnya:}

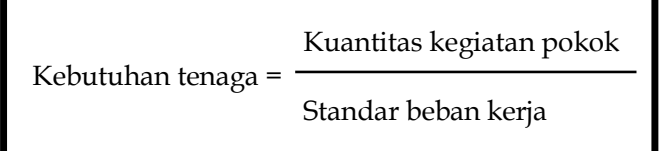

Hasil perhitungan kebutuhan tenaga setiap kegiatan pokok kemudian dikalikan dengan FKK dan ditambahkan dengan FKI, untuk mendapatkan jumlah kebutuhan tenaga secara keseluruhan.

Data yang diperlukan :

a. Waktu yang tersedia

b. Standar beban kerja

c. Standar kelonggaran

d. Kuantitas kegiatan pokok tiap unit kerja selama 1 tahun

Penelitian yang menggunakan metode WISN dalam mengukur beban kerja telah banyak dilakukan antara lain oleh Nurul Fitriah (2016), Philip Govule et.al (2015), Anuja Awadh (2015), Naga Satish et.al (2015), Mehdi Abideh et.al (2014), Dharmayuda (2014) dan Saikat Das et.al (2013). Penelitian-penelitian tersebut dilakukan pada berbagai kategori SDM Kesehatan yang berbeda. Beberapa penelitian mendapatkan hasil beban kerja yang tinggi pada kategori tenaga kesehatan yang diteliti, namun ada pula yang menemukan beban kerja rendah sehingga terjadi overload tenaga.
Pengembangan Sumber Daya Manusia Kesehatan

Pengembangan

(development)

adalah penyiapan individu untuk memikul tanggung jawab yang berbeda atau yang lebih tinggi di dalam organisasi. Pengembangan biasanya berhubungan dengan kemampuan intelektual atau emosional yang diperlukan untuk melaksanakan pekerjaan yang lebih baik. Pengembangan membantu para karyawan mempersiapkan diri menghadapi perubahan di pekerjaan mereka yang dapat diakibatkan oleh teknologi baru, desain pekerjaan, pelanggan baru atau pasar produk baru (Simamora, 2006:273). Pada tahap awal organisasi perlu melakukan fase penilaian yang ditandai dengan kegiatan analisis kebutuhan pelatihan (training need analysis). Terdapat tiga situasi dimana organisasi dipandang perlu melakukan analisis kebutuhan pelatihan yaitu: perfomance problem, new system and technology serta automatic and habitual training. Kondisi pertama berkaitan dengan kinerja dimana karyawan organisasi mengalami degradasi kualitas atau kesenjangan antara kinerja dengan standar kerja yang ditetapkan. Analisis kebutuhan pengembangan SDM dapat dilakukan melalui pendekatan analisis organisasi (organizational analysis) yang menilai unit atau bagian dari organisasi yang memerlukan pengembangan, analisis 
tugas (task/job analysis) yang memilih siapa orang yang akan mengidentifikasi pekerjaan atau skill apa dikembangkan (Simamora, 2006:289yang harus dipelajari, dan analisis orang 292). (person analysis) yang membantu

\section{Kerangka Konseptual}

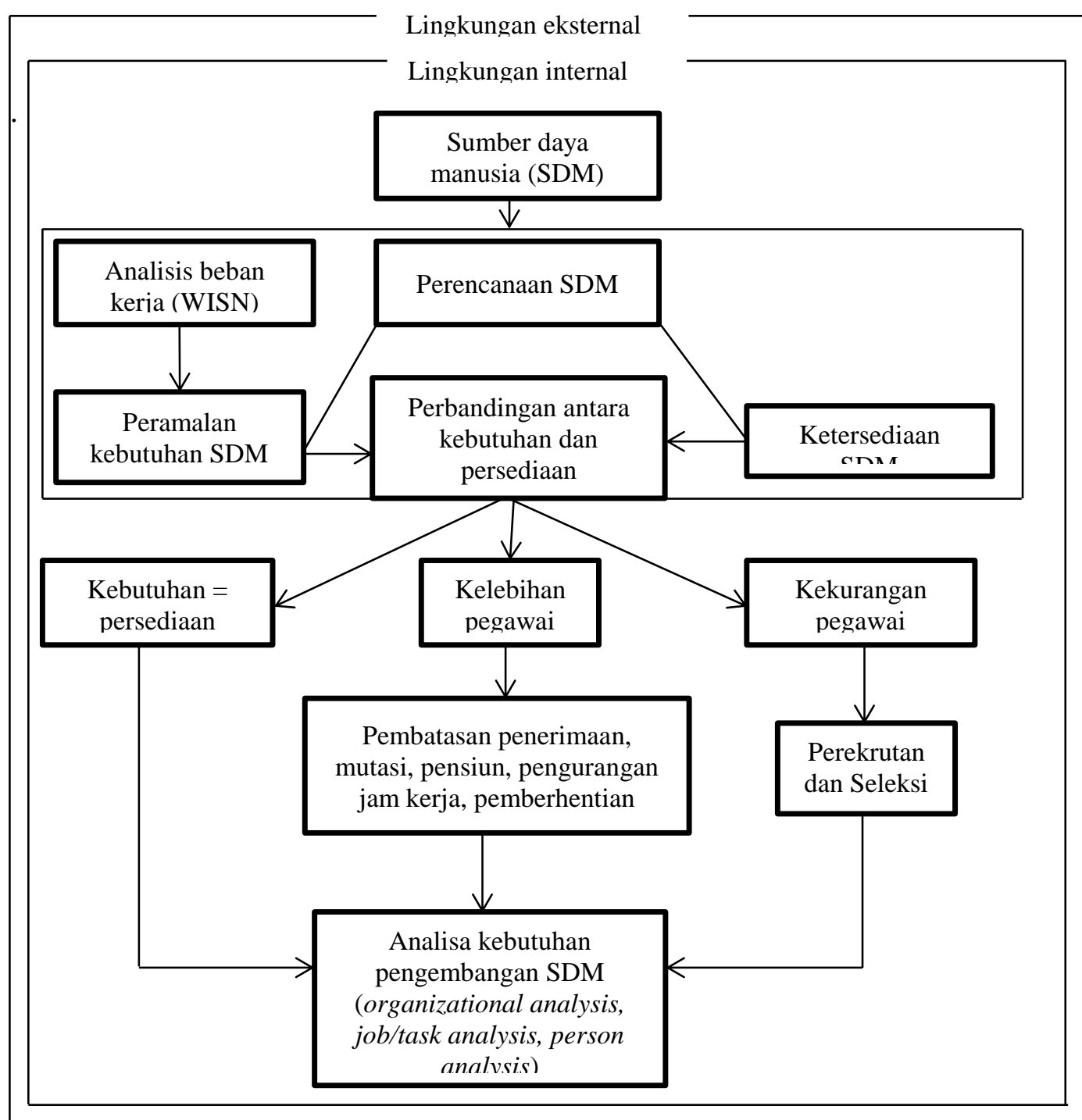

Sumber : Dimodifikasi dan diterjemahkan dari "What is Human Resources Strategy" Mark A.Thomas, 2011; Mangkunegara, 2003; Simamora, 2006.

\section{METODE PENELITIAN}

Penelitian ini merupakan penelitian deskriptif dengan pendekatan kuantitatif dan kualitatif. Pendekatan kuantitatif digunakan untuk menghitung beban kerja dan kebutuhan SDMK Puskesmas dengan metode WISN. Data kualitatif digunakan dalam melakukan analisis kebutuhan pengembangan SDMK melalui analisis kebutuhan organisasi, analisis kebutuhan 
pekerjaan dan analisis kebutuhan personal. Populasi dalam penelitian ini adalah seluruh Puskesmas yang ada di Kabupaten Lombok Barat sebanyak 17 Puskesmas. Sampel Puskesmas dipilih dengan purposive sampling dengan mempertimbangkan status Puskesmas (satu Puskesmas rawat jalan dan satu Puskesmas rawat inap), jumlah kunjungan terbanyak berdasarkan data kunjungan tahun 2015 dan sudah terakreditasi. Berdasarkan kriteria tersebut terpilih Puskesmas Gunung Sari dan Puskesmas Meninting. Seluruh SDM yang ada di kedua Puskesmas dijadikan responden yaitu sebanyak 168 orang, 98 orang dari Puskesmas Gunung Sari dan 70 orang dari Puskesmas Meninting. Data kualitatif didapatkan dari pemilihan 10 informan penelitian yang berasal dari kedua Puskesmas dengan kriteria seseorang yang terlibat dalam upaya perencanaan dan pengembangan SDMK Puskesmas.

Data kuantitatif dikumpulkan dengan menggunakan angket yang berisi template kegiatan pokok dan tambahan setiap kategori SDMK Puskesmas. Sedangkan data kualitatif digali melalui wawancara mendalam dan Focus Group Discussion (FGD). Analisa data kuantitatif dilakukan dengan menggunakan metode WISN untuk mengukur beban kerja dan kebutuhan setiap unit dan kategori SDMK. Analisa data kualitatif menggunakan tahapan analisis menurut Miles dan Huberman (1984) dalam Sugiyono (2011;246), yang meliputi reduksi data, penyajian data dan verifikasi data. Teknik triangulasi metode digunakan untuk menguji validitas internal data wawancara melalui FGD.

\section{HASIL PENELITIAN DAN PEMBAHASAN}

\section{Karakteristik Responden}

Karakteristik umur responden didominasi oleh umur yang relatif masih muda yaitu berumur 20-29 tahun, sebanyak 71 orang atau $42,3 \%$. Kondisi ini terjadi karena lebih dari sepertiga SDMK Puskesmas yang ada adalah tenaga yang direkrut menjadi pegawai BLUD dan rata-rata berusia dibawah 30 tahun atau baru menyelesaikan jenjang pendidikan terakhirnya. Karakteristik jenis kelamin responden sebagian besar terdiri atas jenis kelamin perempuan, yaitu berjumlah 118 orang atau 70,2\% . Komposisi kategori tenaga kesehatan yang ada di Puskesmas sebagian besar diisi oleh bidan dan perawat, dimana kategori bidan seluruhnya berjenis kelamin perempuan.

Sebagian besar responden berpendidikan Diploma III, yaitu berjumlah 73 orang atau 43,5\%. Standar kompetensi yang diamanatkan UndangUndang untuk seluruh tenaga kesehatan yang ada di Puskesmas (bidan, perawat, perawat gigi, tenaga farmasi, tenaga gizi, 
analis laboratorium dan sanitarian) adalah minimal setingkat Diploma III sehingga menyebabkan distribusi latar belakang pendidikan tenaga yang dominan ada di Puskesmas adalah Diploma III. Masa kerja kurang dari 5 tahun mendominasi karakteristik masa kerja responden yaitu berjumlah 70 orang atau $41,7 \%$, disebabkan oleh komposisi tenaga BLUD yang dominan. Sebagian besar responden memiliki status kepegawaian sebagai PNS yaitu sebanyak 92 orang atau $54,8 \%$, kemudian diikuti oleh tenaga kontrak yang terdiri atas tenaga kontrak Pemda dan BLUD sebanyak 66 orang atau $39,2 \%$.

\section{Kategori Sumber Daya Manusia Kesehatan (SDMK)}

Puskesmas Gunung Sari memiliki 19 kategori tenaga yang meliputi: Pemimpin UPT BLUD Puskesmas, kepala tata usaha, dokter umum, dokter gigi, perawat gigi, perawat, bidan, tenaga farmasi, analis laboratorium, tenaga sarjana kesehatan masyarakat, sanitarian, tenaga gizi, tenaga administrasi tata usaha, tenaga administrasi keuangan, tenaga administrasi loket dan rekam medik, cleaning service, satpam/penjaga malam, sopir dan juru masak. Sedangkan Puskesmas Meninting memiliki 18 kategori tenaga yang sama dengan Puskesmas Gunung Sari kecuali juru masak. Hal ini disebabkan oleh perbedaan status Puskesmas dimana Puskesmas
Meninting merupakan Puskesmas rawat jalan sehingga tidak membutuhkan tenaga juru masak seperti Puskesmas rawat inap.

\section{Unit Kerja}

Jumlah unit kerja yang ada di Puskesmas Gunung Sari sebanyak 17 unit dan Puskesmas Meninting 16 unit, dimana unit rawat inap tidak dimiliki oleh Puskesmas Meninting karena merupakan Puskesmas rawat jalan atau non rawat inap. Unit-unit tersebut adalah: Loket, Poli Gigi, Poli Dewasa dan Remaja, Poli Anak, Poli KIA-KB, Rawat Inap, Bersalin, Unit Gawat Darurat (UGD), Apotek, Laboratorium, Tata Usaha, Upaya Kesehatan Masyarakat (UKM) Esensial, Upaya Kesehatan Masyarakat (UKM) Pengembangan, Tenaga lainnya, Kepala Puskesmas, Puskesmas Pembantu (Pustu) dan Pos Kesehatan Desa (Poskesdes). Masing-masing unit kerja terdiri atas satu atau lebih kategori tenaga. Waktu Kerja Tersedia (WKT)

Unsur-unsur yang harus
diperhatikan dalam menghitung WKT
adalah: hari kerja pertahun, cuti tahunan,
pendidikan dan pelatihan, libur nasional,
ketidakhadiran karena sakit, ijin, atau
keperluan lainnya, dan waktu bekerja
setiap kategori tenaga setiap harinya.
Berdasarkan hal tersebut rata-rata WKT
yang dimiliki kategori tenaga yang ada di
Puskesmas Gunung Sari adalah 1.378,5
jam/tahun dengan WKT tertinggi dimiliki
oleh tenaga sopir dan WKT terendah
p-ISSN 2460-9749
e-ISSN 2620-5890


dimiliki ole Pemimpin UPT BLUD

Puskesmas. Kategori tenaga di Puskesmas

Meninting memiliki rata-rata WKT
$1.357,8 \mathrm{jam} /$ tahun, dengan WKT tertinggi dimiliki oleh tenaga sopir dan WKT terendah dimiliki tenaga dokter gigi.

\section{Beban Kerja dan Kebutuhan (SDMK)}

Tabel 1.1. Beban Kerja dan Kebutuhan (SDMK) Setiap Unit Kerja

\begin{tabular}{|c|c|c|c|c|c|c|c|c|c|c|}
\hline \multirow[t]{2}{*}{ No. } & \multirow[t]{2}{*}{ Unit kerja } & \multirow{2}{*}{$\begin{array}{l}\text { Kategori SDMK } \\
\text { dalam unit kerja }\end{array}$} & \multicolumn{4}{|c|}{ Puskesmas Gunung Sari } & \multicolumn{4}{|c|}{ Puskesmas Meninting } \\
\hline & & & $\begin{array}{l}\text { Ters } \\
\text { edia }\end{array}$ & $\begin{array}{l}\text { Dibutu } \\
\text { hkan }\end{array}$ & Gap & $\begin{array}{l}\text { Rasio } \\
\text { WISN } \\
\end{array}$ & $\begin{array}{l}\text { Ters } \\
\text { edia }\end{array}$ & $\begin{array}{c}\text { Dibutu } \\
\text { hkan }\end{array}$ & Gap & $\begin{array}{l}\text { Rasio } \\
\text { WISN }\end{array}$ \\
\hline 1. & Loket & $\begin{array}{l}\text { Tenaga } \\
\text { administrasi loket } \\
\text { dan rekam medik }\end{array}$ & 7 & 9 & -2 & 0,8 & 4 & 3 & +1 & 1,3 \\
\hline \multirow[t]{2}{*}{2.} & \multirow[t]{2}{*}{ Poli gigi } & Dokter gigi & 1 & 2 & -1 & 0,5 & 1 & 1 & 0 & 1 \\
\hline & & Perawat gigi & 2 & 2 & 0 & 1 & 3 & 1 & +2 & 3 \\
\hline \multirow[t]{2}{*}{3.} & \multirow{2}{*}{$\begin{array}{l}\text { Poli dewasa } \\
\text { dan remaja }\end{array}$} & Dokter umum & 2 & 5 & -3 & 0,4 & 1 & 2 & -1 & 0,5 \\
\hline & & Perawat & 5 & 7 & -2 & 0,7 & 2 & 2 & 0 & 1 \\
\hline \multirow[t]{2}{*}{4.} & \multirow[t]{2}{*}{ Poli anak } & Dokter umum & 0 & 2 & -2 & 0 & 0 & 1 & -1 & 0 \\
\hline & & Perawat & 1 & 3 & -2 & 0,3 & 2 & 1 & +1 & 2 \\
\hline \multirow[t]{2}{*}{5.} & \multirow[t]{2}{*}{ Poli KIA-KB } & Dokter umum & 0 & 1 & -1 & 0 & 0 & 1 & -1 & 0 \\
\hline & & Bidan & 4 & 1 & +3 & 4 & 5 & 2 & +3 & 2,5 \\
\hline \multirow[t]{2}{*}{6.} & \multirow[t]{2}{*}{ Rawat inap } & Dokter umum & 0 & 1 & -1 & 0 & - & - & - & - \\
\hline & & Perawat & 0 & 1 & -1 & 0 & - & - & - & - \\
\hline \multirow[t]{2}{*}{7.} & \multirow[t]{2}{*}{ Bersalin } & Dokter umum & 0 & 1 & -1 & 0 & 0 & 1 & -1 & 0 \\
\hline & & Bidan & 10 & 7 & +3 & 1,4 & 5 & 5 & 0 & 1 \\
\hline \multirow[t]{2}{*}{8.} & \multirow{2}{*}{$\begin{array}{l}\text { Unit gawat } \\
\text { darurat }\end{array}$} & Dokter umum & 1 & 4 & -3 & 0,3 & 1 & 2 & -1 & 0,5 \\
\hline & & Perawat & 15 & 15 & 0 & 1 & 6 & 11 & -5 & 0,5 \\
\hline 9. & Apotek & Tenaga farmasi & 4 & 6 & -2 & 0,7 & 4 & 5 & -1 & 0,8 \\
\hline 10. & Laboratorium & $\begin{array}{l}\text { Analis } \\
\text { laboratorium }\end{array}$ & 4 & 4 & 0 & 1 & 2 & 3 & -1 & 0,7 \\
\hline \multirow[t]{3}{*}{11.} & \multirow[t]{3}{*}{ Tata usaha } & Kepala tata usaha & 1 & 2 & -1 & 0,5 & 1 & 1 & 0 & 1 \\
\hline & & $\begin{array}{l}\text { Tenaga } \\
\text { administrasi tata } \\
\text { usaha }\end{array}$ & 1 & 1 & 0 & 1 & 2 & 1 & +1 & 2 \\
\hline & & $\begin{array}{l}\text { Tenaga } \\
\text { administrasi } \\
\text { keuangan }\end{array}$ & 3 & 1 & +2 & 3 & 3 & 1 & +2 & 3 \\
\hline \multirow[t]{5}{*}{12.} & \multirow{5}{*}{$\begin{array}{l}\text { Upaya } \\
\text { kesehatan } \\
\text { masyarakat } \\
\text { esensial }\end{array}$} & $\begin{array}{l}\text { Sarjana kesehatan } \\
\text { masyarakat }\end{array}$ & 2 & 1 & +1 & 2 & 2 & 1 & +1 & 2 \\
\hline & & Tenaga gizi & 4 & 4 & 0 & 1 & 3 & 2 & +1 & 1,5 \\
\hline & & Sanitarian & 2 & 1 & +1 & 2 & 1 & 1 & 0 & 1 \\
\hline & & Perawat & 6 & 2 & +4 & 3 & 4 & 3 & +1 & 1,3 \\
\hline & & Dokter umum & 1 & 2 & -1 & 0,5 & - & - & - & - \\
\hline 13. & $\begin{array}{l}\text { Upaya } \\
\text { kesehatan } \\
\text { masyarakat } \\
\text { pengembanga } \\
\mathrm{n}\end{array}$ & Perawat & 1 & 2 & -1 & 0,5 & 0 & 2 & -2 & 0 \\
\hline \multirow[t]{4}{*}{14.} & \multirow{4}{*}{$\begin{array}{l}\text { Tenaga } \\
\text { lainnya }\end{array}$} & Cleaning service & 4 & 2 & +2 & 2 & 2 & 2 & 0 & 1 \\
\hline & & Sopir & 1 & 1 & 0 & 1 & 1 & 1 & 0 & 1 \\
\hline & & $\begin{array}{l}\text { Satpam/ penjaga } \\
\text { malam }\end{array}$ & 2 & 4 & -2 & 0,5 & 1 & 2 & -1 & 0,5 \\
\hline & & Juru masak & 1 & 1 & 0 & 1 & - & - & - & - \\
\hline 15. & $\begin{array}{l}\text { Kepala } \\
\text { Puskesmas }\end{array}$ & $\begin{array}{l}\text { Pemimpin UPT } \\
\text { BLUD Puskesmas }\end{array}$ & 1 & 1 & 0 & 1 & 1 & 2 & -1 & 0,5 \\
\hline 16. & $\begin{array}{l}\text { Puskesmas } \\
\text { pembantu } \\
\text { (Pustu) }\end{array}$ & Perawat & 3 & 4 & -1 & 0,8 & 3 & 6 & -3 & 0,5 \\
\hline 17. & $\begin{array}{l}\text { Pos kesehatan } \\
\text { desa } \\
\text { (Poskesdes) }\end{array}$ & Bidan & 9 & 17 & -8 & 0,5 & 10 & 24 & -14 & 0,4 \\
\hline
\end{tabular}

Sumber : Data Primer diolah, 2017 
Berdasarkan Tabel 1.1. terdapat 8 unit kerja di Puskesmas Gunung Sari yang seluruh kategori tenaganya memiliki beban kerja tinggi (rasio WISN<1) yaitu: Loket, Poli Dewasa dan Remaja, Poli Anak, Rawat Inap, Apotek, UKM Pengembangan, Pustu dan Poskesdes. Terdapat 2 unit dengan beban kerja rendah (rasio WISN>1) yaitu Laboratorium dan Kepala Puskesmas. Unit-Unit lainnya memiliki beban kerja yang bervariasi antar kategori tenaga yang ada di dalamnya.

Terdapat 7 unit kerja yang memiliki beban kerja tinggi (rasio WISN<1) yaitu: UGD, Apotek, Laboratorium, UKM Pengembangan, Kepala Puskesmas, Pustu dan Poskesdes. Terdapat 1 unit kerja yang memiliki beban kerja rendah (rasio WISN <1) yaitu Loket. Unit kerja yang lain memiliki variasi beban kerja pada setiap kategori tenaga yang ada didalamnya.

Tabel 1.2. Kebutuhan dan Rasio WISN Setiap Kategori SDMK Puskesmas Gunung Sari

\begin{tabular}{|c|c|c|c|c|c|c|}
\hline Kategori Tenaga & $\begin{array}{l}\text { Kebutuhan } \\
\text { SDMK }\end{array}$ & FKI & $\begin{array}{l}\text { Jumlah } \\
\text { kebutuhan } \\
\text { setiap } \\
\text { kategori } \\
\text { SDMK } \\
\end{array}$ & $\begin{array}{l}\text { Tenaga } \\
\text { tersedia }\end{array}$ & $\begin{array}{l}\text { Gap } \\
\text { ketersediaan } \\
\text { dan kebutuhan } \\
\text { tenaga }\end{array}$ & Rasio WISN \\
\hline $\begin{array}{l}\text { Tenaga } \\
\text { administrasi loket } \\
\text { dan RM }\end{array}$ & 9,58 & - & $9,58(9)$ & 7 & -2 & 0,8 \\
\hline Dokter gigi & 1,71 & - & $1,71(2)$ & 1 & -1 & 0,5 \\
\hline Perawat gigi & 2,17 & - & $2,17(2)$ & 2 & 0 & 1 \\
\hline Dokter umum & 13,00 & 0,08 & $13,08(13)$ & 4 & -9 & 0,3 \\
\hline Perawat & 33,03 & 0,41 & $33,44(34)$ & 31 & -3 & 0,9 \\
\hline Bidan & 25,03 & 0,01 & $25,04(25)$ & 23 & -2 & 0,9 \\
\hline Tenaga farmasi & 5,56 & 0,02 & $5,58(6)$ & 4 & -2 & 0,7 \\
\hline $\begin{array}{l}\text { Analis } \\
\text { laboratorium }\end{array}$ & 3,99 & 0,06 & $4,05(4)$ & 4 & 0 & 1 \\
\hline Kepala tata usaha & 1,31 & - & $1,31(2)$ & 1 & -1 & 0,5 \\
\hline $\begin{array}{l}\text { Tenaga } \\
\text { administrasi tata } \\
\text { usaha }\end{array}$ & 0,48 & - & $0,48(1)$ & 1 & 0 & 1 \\
\hline $\begin{array}{l}\text { Tenaga } \\
\text { administrasi } \\
\text { keuangan } \\
\end{array}$ & 0,55 & - & $0,55(1)$ & 3 & +2 & 3 \\
\hline Tenaga gizi & 3,61 & 0,46 & $4,07(4)$ & 4 & 0 & 1 \\
\hline SKM & 0,41 & - & $0,41(1)$ & 2 & +1 & 2 \\
\hline Sanitarian & 0,19 & - & $0,19(1)$ & 2 & +1 & 2 \\
\hline Sopir & 0,49 & - & $0,49(1)$ & 1 & 0 & 1 \\
\hline Cleaning service & 1,28 & - & $1,28(2)$ & 4 & +2 & 2 \\
\hline Satpam & 3,99 & - & $3,99(4)$ & 2 & -2 & 0,5 \\
\hline Juru masak & 0,31 & - & $0,31(1)$ & 1 & 0 & 1 \\
\hline $\begin{array}{l}\text { Pemimpin UPT } \\
\text { BLUD Puskesmas }\end{array}$ & 0,51 & 0,02 & $0,53(1)$ & 1 & 0 & 1 \\
\hline \multicolumn{3}{|c|}{ SDMK Puskesmas Gunung Sari } & 114 & 98 & -16 & 0,86 \\
\hline
\end{tabular}

Sumber: Data Primer diolah, 2017

Berdasarkan Tabel 1.2 tampak bahwa kebutuhan seluruh SDMK Puskesmas Gunung Sari adalah 114 orang, sementara yang tersedia 98 orang. Terdapat 8 kategori tenaga yang memiliki beban kerja tinggi (rasio WISN<1) yaitu: 
tenaga administrasi loket dan rekam tata usaha, dan satpam yang medik, dokter gigi, dokter umum, membutuhkan tambahan tenaga. perawat, bidan, tenaga farmasi, kepala

Tabel 1.3. Kebutuhan dan Rasio WISN Setiap Kategori SDMK Puskesmas Meninting

\begin{tabular}{|c|c|c|c|c|c|c|}
\hline Kategori tenaga & $\begin{array}{l}\text { Kebutuhan } \\
\text { SDMK }\end{array}$ & FKI & $\begin{array}{l}\text { Jumlah } \\
\text { kebutuhan } \\
\text { setiap } \\
\text { kategori } \\
\text { SDMK } \\
\end{array}$ & $\begin{array}{l}\text { Tenaga } \\
\text { tersedia }\end{array}$ & $\begin{array}{l}\text { Gap } \\
\text { ketersediaan } \\
\text { dan } \\
\text { kebutuhan } \\
\text { tenaga } \\
\end{array}$ & $\begin{array}{l}\text { Rasio } \\
\text { WISN }\end{array}$ \\
\hline $\begin{array}{l}\text { Tenaga } \\
\text { administrasi loket } \\
\text { dan RM }\end{array}$ & 3,30 & - & $3,30(3)$ & 4 & +1 & 1,3 \\
\hline Dokter gigi & 0,72 & - & $0,72(1)$ & 1 & 0 & 1 \\
\hline Perawat gigi & 0,62 & - & $0,62(1)$ & 3 & +2 & 3 \\
\hline Dokter umum & 5,48 & 0,08 & $5,56(6)$ & 2 & -4 & 0,3 \\
\hline Perawat & 22,63 & 0,55 & $23,18(23)$ & 17 & -6 & 0,7 \\
\hline Bidan & 30,69 & 0,01 & $30,70(31)$ & 20 & -11 & 0,6 \\
\hline Tenaga farmasi & 4,82 & 0,02 & $4,84(5)$ & 4 & -1 & 0,8 \\
\hline $\begin{array}{l}\text { Analis } \\
\text { laboratorium }\end{array}$ & 2,29 & 0,06 & $2,35(3)$ & 2 & -1 & 0,7 \\
\hline Kepala tata usaha & 0,17 & - & $0,17(1)$ & 1 & 0 & 1 \\
\hline $\begin{array}{l}\text { Tenaga } \\
\text { administrasi tata } \\
\text { usaha }\end{array}$ & 0,39 & - & $0,39(1)$ & 2 & +1 & 2 \\
\hline $\begin{array}{l}\text { Tenaga } \\
\text { administrasi } \\
\text { keuangan }\end{array}$ & 0,22 & - & $0,22(1)$ & 3 & +2 & 3 \\
\hline Tenaga gizi & 1,59 & 0,32 & $1,91(2)$ & 3 & +1 & 1,5 \\
\hline SKM & 0,22 & - & $0,22(1)$ & 2 & +1 & 2 \\
\hline Sanitarian & 0,19 & - & $0,19(1)$ & 1 & 0 & 1 \\
\hline Sopir & 0,55 & - & $0,55(1)$ & 1 & 0 & 1 \\
\hline Cleaning service & 1,29 & - & $1,29(2)$ & 2 & 0 & 1 \\
\hline Satpam & 1,32 & - & $1,32(2)$ & 1 & -1 & 0,5 \\
\hline $\begin{array}{l}\text { Pemimpin UPT } \\
\text { BLUD } \\
\text { Puskesmas }\end{array}$ & 2,02 & 0,02 & $2,04(2)$ & 1 & -1 & 0,5 \\
\hline \multicolumn{3}{|c|}{ SDMK Puskesmas Meninting } & 87 & 70 & -17 & 0,8 \\
\hline
\end{tabular}

Sumber: Data Primer diolah, 2017

\section{Berdasarkan Tabel 1.3. Puskesmas} Meninting memiliki kebutuhan SDMK sebanyak 87 orang, sementara yang tersedia 70 orang. Terdapat 7 kategori tenaga dengan beban kerja tinggi (rasio WISN<1) yaitu: dokter umum, perawat, bidan, tenaga farmasi, analis laboratorium, satpam/penjaga malam dan pemimpin UPT BLUD Puskesmas yang memerlukan tambahan tenaga.

Hasil analisis menunjukkan terdapat kategori tenaga yang masih merangkap tugas pada unit yang berbeda dalam waktu bersamaan dan tugas-tugas tambahan yang bersifat administratif dalam unit kerja cukup banyak. Menurut WHO (2010) dalam menganalisis hasil WISN harus diperhatikan faktor-faktor yang mempengaruhi beban kerja tinggi seperti: jumlah SDMK yang kurang, komposisi pekerjaan yang tidak proporsional, atau kompetensi tenaga 
yang ditempatkan di unit kerja Puskesmas tidak sesuai standar. Penelitian yang dilakukan oleh Philip Govule et.al (2015) dan Pia Liljamo (2016) menemukan bahwa tingginya beban kerja tenaga kesehatan disebabkan oleh tugas-tugas tambahan diluar tugas profesional yang mereka miliki. Sementara penelitian yang dilakukan oleh Putri Julia (2014) dan Utara Hartawan (2015) menemukan bahwa tingginya beban kerja tenaga kesehatan disebabkan karena unsur jumlah tenaga yang tersedia belum memadai, sehingga perlu dilakukan perekrutan tenaga baru.

\section{Kebutuhan Pengembangan SDMK}

Hasil needs assesesment yang didapatkan melalui wawancara dan FGD dengan metode analisis kebutuhan organisasi, analisis kebutuhan pekerjaan dan analisis kebutuhan personal, didapatkan hasil kebutuhan pengembangan SDMK di Puskesmas Gunung Sari dan Meninting dibagi dalam 4 kategori yaitu: peningkatan jenjang pendidikan formal untuk tenaga perawat SPK minimal setingkat Diploma III, pelatihan kegawatdaruratan (ATLS, ACLS, BTCLS), pelatihan penunjang diagnostik (USG, EKG, Refraksionis), pelatihan manajemen dan administrasi (pelatihan bendahara BLUD, tenaga pengadaan barang dan jasa, service exelent dan kursus Bahasa Inggris). Dalam hal ini Puskesmas sudah memiliki anggaran untuk melakukan pengembangan SDMK, diluar pelatihan dan pengembangan yang difasilitasi oleh Dinas Kesehatan. Melakukan analisis kebutuhan pengembangan SDMK sangat bermanfaat didalam membuat perencanaan pengembangan SDMK agar tepat sasaran, efisien dan efektif. Seperti penelitian yang dilakukan Dzulfiqar (2016) tentang bagaimana Sumber Daya Manusia dapat mempengaruhi produktivitas tenaga kerja. Dalam penelitian tersebut ditemukan bahwa pelatihan diberikan untuk meningkatkan keahlian melaksanakan pekerjaan sesuai dengan tugas-tugas yang diberikan.

\section{KESIMPULAN DAN SARAN}

\section{Kesimpulan}

Terdapat 8 unit kerja dan 8 kategori tenaga di Puskesmas Gunung Sari yang memiliki tekanan beban kerja tinggi (rasio WISN<1) yang membutuhkan tambahan tenaga. Kebutuhan SDMK Puskesmas Gunung Sari keseluruhan sebanyak 114 orang. Berdasarkan analisis kebutuhan organisasi, analisis kebutuhan pekerjaan dan analisis kebutuhan personal, kebutuhan pengembangan Puskesmas Gunung Sari terdiri atas kebutuhan peningkatan kompetensi tenaga perawat SPK menjadi Diploma III, kebutuhan pelatihan kegawatdaruratan BTCLS, ACLS dan ATLS. Pelatihan penunjang dignostik seperti USG, EKG 
dan refraksionis. Puskesmas Gunung Sari juga membutuhkan pelatihan manajemen dan administrasi bagi bendahara BLUD, tenaga pengadaan barang dan jasa serta service exelent bagi seluruh tenaga Puskesmas.

Hasil WISN menunjukkan terdapat 7 unit kerja dan 7 kategori tenaga yang memiliki tekanan beban kerja tinggi (rasio WISN<1) di Puskesmas Meninting. Kebutuhan tenaga Puskesmas Meninting secara keseluruhan sebanyak 87 orang. Pengembangan SDMK yang dibutuhkan Puskesmas Meninting berdasarkan analisis kebutuhan organisasi, analisis kebutuhan pekerjaan dan analisis kebutuhan personal terdiri atas kebutuhan peningkatan kompetensi tenaga perawat SPK menjadi Diploma III, kebutuhan pelatihan kegawatdaruratan BTCLS, ATLS dan ACLS. Pelatihan lainnya yang dibutuhkan adalah pelatihan manajemen dan administrasi untuk tenaga bendahara BLUD, pelatihan tenaga pengadaan barang dan jasa, serta pelatihan service exelent dan Bahasa Inggris untuk seluruh staf.

\section{Saran}

1. Setiap Puskesmas perlu melakukan analisis perencanaan SDMK untuk setiap unit dan kategori tenaga yang ada agar jumlah, distribusi, dan kompetensinya sesuai dengan beban kerja yang ada.
2. Puskesmas dapat menggunakan metode WISN dalam menghitung beban kerja dan jumlah kebutuhan SDMK serta metode needs assesement, yaitu analisis kebutuhan organisasi (organizational analysis), analisis kebutuhan pekerjaan (task/job analysis) dan analisis kebutuhan personal (person analysis) dalam menghitung kebutuhan pengembangan SDMK Puskesmas.

3. Metode pengambilan data primer untuk mengukur beban kerja yang digunakan dalam penelitian ini adalah daily log yaitu dengan angket berupa template kegiatan, metode ini sangat bergantung dengan kerjasama dan kejujuran responden dalam mengisi angket. Penelitian selanjutnya disarankan menggunakan metode observasi seperti work sampling atau time motion study agar standar beban kerja yang didapatkan lebih rinci dan spesifik.

\section{DAFTAR PUSTAKA}

Anuja Awadh, P\& Swati Chandel, (2015), "Human Resource Assessement of District Hospital Applying WISN Method: Role of Laboratory Technicians", International Journal of Medicine and Public Health, vol.3, iss. 4 pp: 267-270

Benhard, R.L.dkk, (2015), "Perencanaan Kebutuhan Sumber Daya Manusia di Puskesmas Kabupaten 
Minahasa", JIKMU. Vol.5, no.1, pp: $43-53$

Dharmayuda, Agung, (2014), “Analisis Beban Kerja Dokter Umum Menggunakan Metode Workload Indicators of Staffing Need (WISN) di Puskesmas Se-Kota Denpasar", Pascasarjana Program Magister Kesehatan Masyarakat, Universitas Udayana.

Dzulfiqar Mohamad et.al, (2016), "How Productivity Can Be Affected By Human Capital", International Journal of Engineering Applied Sciences and Technology, vol.1, iss.6, pp: 29-32

Hardjawinata, AH, (2006), “Analisa Kebutuhan Sumber Daya Manusia untuk Bidang Administrasi Rumah Sakit Umum Daerah Budhi Asis". Tesis Program Pasca Sarjana Kajian Administrasi Rumah Sakit Fakultas Kesehatan Masyarakat Universitas Indonesia. Jakarta

Mangkunegara, Anwar Prabu, (2003), Perencanaan dan Pengembangan Sumber Daya Manusia. Bandung: Refika Aditama

Mehdi Abideh, et.al, (2014), "Standard Development of Family Physicians to the Population Defined by WISN", Buletin of Environment Pharmachology and Lyfe Science. Vol.3, no.12, pp: 89-96

Naga Satish, S. et.al, (2015), “Gap Analysis in Staffing Using Workload Indicators of Staffing Need Method in Tertiary Care Teaching Hospital", International Journal of Scientific Research, vol.4, iss: 7, pp: 376-377

Nurul Fitriah, dkk, (2016), "Analisis Kebutuhan Psikiater Berdasarkan Beban Kerja dengan Menggunakan Metode Workload Indicator Staffing Needs (WISN) di Unit
Rawat Jalan Jiwa Rumah Sakit Ernald Bahar Provinsi Sumatera Selatan", Jurnal Kedokteran dan Kesehatan, vol.3, no.1, pp: 347-353

Pia Liljamo, Paivi Lavander, Pirjo Kejonen, (2016), "Determining Optimal Nursing Resources in Relation to Functions During the Qulu University Hospital Nurse Staffing Management Project", IMIA and IOS Press, 658,3-3

Philip Govule, et al, (2015), “Application of Workload Indicators of Staffing Needs (WISN) in Determining Health Workers' Requirements for Mityana General Hospital, Uganda", International Journal of Public Health Research, 3(5): 254263

Putri Julia. Dkk, (2014), “Analisis Kebutuhan Tenaga Perawat Berdasarkan Beban Kerja dengan Menggunakan Metode Workload Indicator Staff Need (WISN) dan Work Sampling", Jurnal Teknik Industri USU, vol.5, no.2, pp:22-25

Saikat Das, et.al, (2013), "A Study to Calculate the Nursing Staff Requirements for The Maternity Ward of Medical College Hospital, Kolkata Applying WISN Method". IOSR Journal of Dental and Medical Sciences. Vol.8, iss.3, pp: 01-07

Shipp, P.J, (1998), Workload Indicators of Staffing Need (WISN): Manual for Implementation. Boston. USA: Initiatives Inc

Simamora, Henry, (2006), Manajemen Sumber Daya Manusia, Edisi ke-3. Cetakan ke-2, Yogyakarta: STIE YKPN.

Sugiyono, (2011), Metode Penelitian Kuantitatif Kualitatif dan $R \& D$. Bandung: Alfabeta 
Utara Hartawan. I.G.A Gede, (2016), “ Analisis Kebutuhan Perawat Berdasarkan Pengamatan Terhadap Penanganan Pasien Dewasa dan Anak-Anak di Unit Gawat Darurat Rumah Sakit Bali Royal", Online Jurnal Universitas Udayana, vol.47, no.2, pp:116-125

WHO, (2010), Workload Indicator Of Staffing Need, Jeneva: WHO Press.

$\underline{\text { Publikasi Organisasi dan Produk Hukum }}$

Departemen Kesehatan RI dan GTZ (2009), Perlengkapan Kerja WISN : Perlengkapan Untuk Pengembangan Indikator Beban Kerja Petugas (WISN) Untuk Memperbaiki Perencanaan Dan Manajemen Tenaga Kerja Kesehatatan Dalam Sistem Kesehatan Yang Di Desentralisasi, Jakarta: BPPSDM Kesehatan.

.(2013), Keputusan Menteri Koordinator Bidang Kesejahteraan Rakyat Republik Indonesia Nomor. 54 Tahun 2013, tentang Rencana Pengembangan Tenaga Kesehatan Tahun 2011-2025, Jakarta: KepMenKoBidKesra.

.(2014), Peraturan Menteri Kesehatan Republik Indonesia Nomor 75 Tahun 2014 Pusat Kesehatan Masyarakat, Jakarta: Kementerian Kesehatan RI.

.(2015), Peraturan Menteri Kesehatan Republik Indonesia Nomor.33 Tahun 2015 tentang Pedoman Penyusunan Perencanaan Kebutuhan Sumber Daya Manusia Kesehatan, Jakarta: Kementrian Kesehatan.

.(2012), Peraturan Pemerintah Republik Indonesia Nomor 64 Tahun 2012 Tentang Sistem Manajemen Sumber Daya Manusia Pada Ombudsman Republik
Indonesia. Jakarta: Pemerintah Republik Indonesia. 